\title{
Molecular and phenotypic characteristics of 15q24 microdeletion in pediatric patients with developmental disorders
}

\author{
Yuanyuan Zhang, Xiaoliang Liu, Haiming Gao, Wanting Cui, Bijun Zhang and Yanyan Zhao*
}

\begin{abstract}
Chromosome 15q24 microdeletion is a rare genetic disorder characterized by development delay, facial dysmorphism, congenital malformations, and occasional autism spectrum disorder (ASD). In this study, we identified five cases of 15q24 microdeletion using multiplex ligation-dependent probe amplification (MLPA) technology in a cohort of patients with developmental delay and/or intellectual disability. Two of these five cases had deletions that overlapped with the previously defined $1.1 \mathrm{Mb}$ region observed in most reported cases. Two cases had smaller deletions $(<0.57 \mathrm{Mb})$ in the $15 \mathrm{q} 24.1$ low copy repeat (LCR) B-C region. They presented significant neurobehavioral features, suggesting that this smaller interval is critical for core phenotypes of 15q24 microdeletion syndrome. One case had minimal homozygous deletion of less than $0.11 \mathrm{Mb}$ in the 15q24.1 LCR B-C region, which contained CYP1A1 (cytochrome P450 family 1 subfamily A member 1) and EDC3 (enhancer of mRNA decapping 3) genes, resulting in poor immunity, severe laryngeal stridor, and lower limbs swelling. This study provides additional evidence of 15q24 microdeletion syndrome with genetic and clinical findings. The results will be of significance to pediatricians in their daily practice.
\end{abstract}

Keywords: 15q24 microdeletion, Developmental delay, MLPA

\section{Introduction}

The rare genetic disorder $15 \mathrm{q} 24$ microdeletion is caused by nonallelic homologous recombination (NAHR) between low copy repeats (LCRs) in the chromosome 15 band q24 region; the overall incidence approaches 1 in 42,000 in the general population [1]. Among subjects with intellectual disability and various congenital defects, the prevalence is approximately 1 in 1751 [2]. To the best of our knowledge, more than 60 patients with $15 \mathrm{q} 24$ deletions have been described in the literature. The majority of $15 \mathrm{q} 24$ microdeletions identified to date involve a 1.1 Mb region between 72.2 and $73.3 \mathrm{Mb}$ of the reference genome (NCBI36/hg18) [3]. A few cases were reported to have atypical deletions, involving only a

*Correspondence: yyzhao@sj-hospital.org

Department of Clinical Genetics, Shengjing Hospital of China Medical

University, Shenyang 110004, Liaoning, China part or none of the proposed $1.1 \mathrm{Mb}$ critical region, but still appeared to be dysfunctional [4]. The clinical spectrum of $15 \mathrm{q} 24$ microdeletion syndrome is variable. Most patients showed developmental delay, intellectual disability, distinctive facial features, and significant speech delay and hypotonia in childhood; some patients manifest eye abnormalities, frequently strabismus, digital anomalies, and dysplastic ears; individual patients also have joint laxity, hearing loss, brain abnormalities, and urogenital malformation symptoms [3].

The 15q24 microdeletion can be detected by molecular methods that determine the copy number of sequences within the deleted region. In China, multiplex ligationdependent probe amplification (MLPA) is a rapid and cost effective method for detection of targeted chromosome copy number variations (CNVs). The process from DNA extraction to capillary electrophoresis can be completed within $24 \mathrm{~h}$ at a cost of 100 to $200 \mathrm{RMB}$. original author(s) and the source, provide a link to the Creative Commons licence, and indicate if changes were made. The images or other third party material in this article are included in the article's Creative Commons licence, unless indicated otherwise in a credit line to the material. If material is not included in the article's Creative Commons licence and your intended use is not permitted by statutory regulation or exceeds the permitted use, you will need to obtain permission directly from the copyright holder. To view a copy of this licence, visit http://creativecommons.org/licenses/by/4.0/. The Creative Commons Public Domain Dedication waiver (http://creativeco mmons.org/publicdomain/zero/1.0/) applies to the data made available in this article, unless otherwise stated in a credit line to the data. 
However, the detection rate of potential pathogenic variation achieved by MLPA is lower than that by microarray. The MLPA P245 probe mix is designed to screen common microdeletion and microduplication syndromes associated with developmental disorders. It contains two probes for the chromosome 15q24 (CYP1A1-2 and SEMA7A-11) region. The MLPA P371 probe mix is specific to this region, including nine probes for the $P M L$ [PML nuclear body scaffold] (2), SEMA7A [semaphorin 7A] (2), CLK3 [CDC like kinase 3] (1), CYP1A1 [cytochrome P450 family 1 subfamily A member 1] (2), CYP1A2 [cytochrome P450 family 1 subfamily A member 2] (1) and CSK [C-terminal Src kinase] (1) genes. The MLPA probe names and their exact locations in the genome are listed in Additional file 1: Table S1, and the locations of related genes are shown in Fig. 1. Here, using MLPA assay, five pediatric patients with developmental disorders were identified to have 15 q24 microdeletions, and the deletion sizes were different. Two carried microdeletions of $<0.57 \mathrm{Mb}$ in the LCR B-C region and showed significant neurobehavioral features. Our results help to delineate the critical region for core phenotypes of 15q24 deletion syndrome.

\section{Methods}

\section{Patients and samples}

A cohort of 7077 cases was enrolled in this study. They were recruited from outpatient department of pediatrics and clinical genetics of Shengiing Hospital of China Medical University. Their ages ranged from 30 days to 12 years. Most presented with developmental disorders (such as motor delay, speech or language delay, and intellectual disability.) Other manifestations were also observed, including congenital malformation, craniofacial abnormalities, and behavioral problems. This study was approved by the Ethics Committee of Shengjing Hospital of China Medical University. Considering these cases were all under the age of 16, written informed consents to participate were obtained from their parents or legal guardians.

\section{Genomic DNA preparation}

Automatic nucleic acid extractor (Allsheng Auto-Pure 32A) was applied to extract genomic DNA from the whole peripheral blood, using a UPure Blood DNA Extraction Kit (M2002-A32; BioBase Technologies Co., LTD). DNA concentration was quantitated using a NanoDrop 1000 (Thermo Scientific, USA). A concentration of $10-50 \mathrm{ng} / \mu \mathrm{L}$ DNA was prepared for MLPA assay.

\section{Multiplex ligation-dependent probe amplification (MLPA) assay}

MLPA assay was carried out in accordance with the manufacturer's instructions. The SALSA P245 probe mix (MRC-Holland, Netherlands) was used to screen for microdeletion/microduplication syndromes as previously described [5]. The SALSA P371 probe mix (MRC-Holland, Netherlands), which encompasses more probes specific for the chromosome 15q24 region, was used to confirm the deletion and infer the deletion size. The amplification products were loaded to ABI 3730 Genetic Analyzer (Applied Biosystems, USA) for capillary electrophoresis. The raw data were generated by the GeneMapper software (Applied Biosystems, USA), and analyzed using the Coffalyser Net software (MRC-Holland, Netherlands).

\section{Results}

\section{Identification of $15 q 24$ microdeletion}

Of the 7077 cases examined by MLPA P245 assay, five were found to have genomic imbalance at 15q24, with a prevalence of 1 in 1429. We named these five cases numbers 1 to 5 . Case 1 was 55 days old; cases 2, 3, 4, and 5 were 2-3 years old. The MLPA P245 results showed that case 1 had homozygous deletion at the CYP1A1-2 probe; cases 2 and 3 had heterozygous deletions at the SEMA7A-11 probe; cases 4 and 5 had heterozygous deletion at both the CYP1A1-2 and

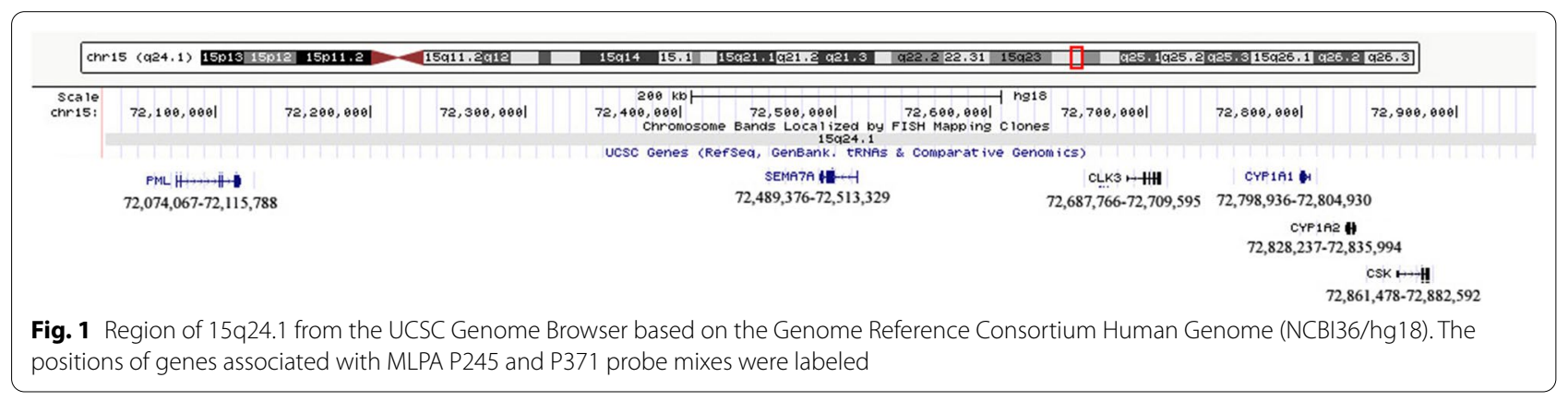


A

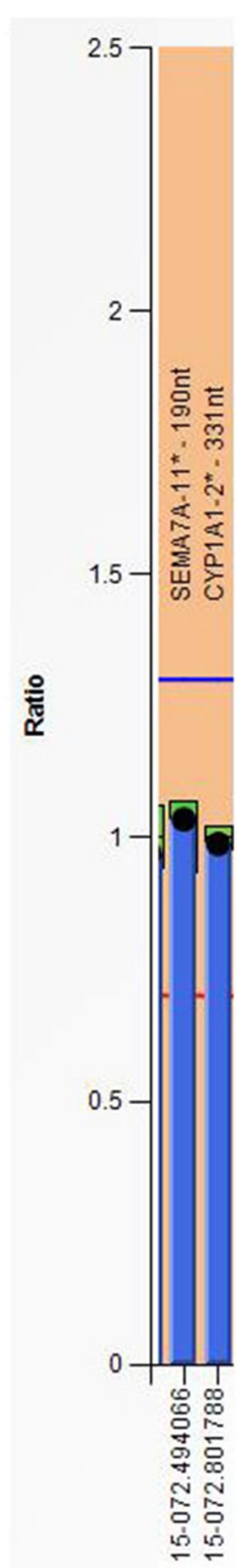

B

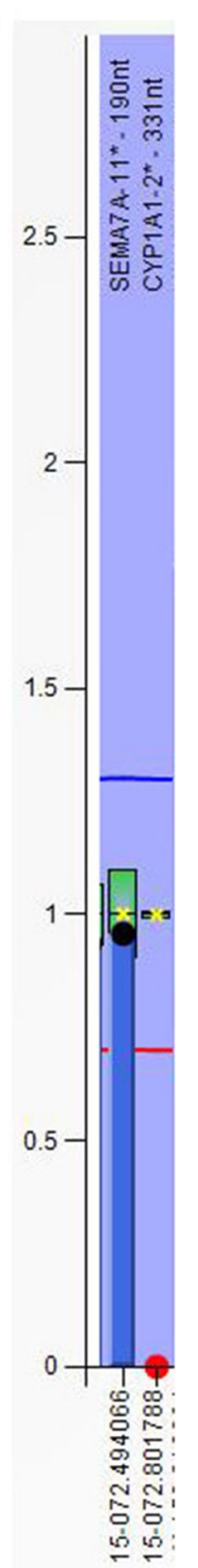

C

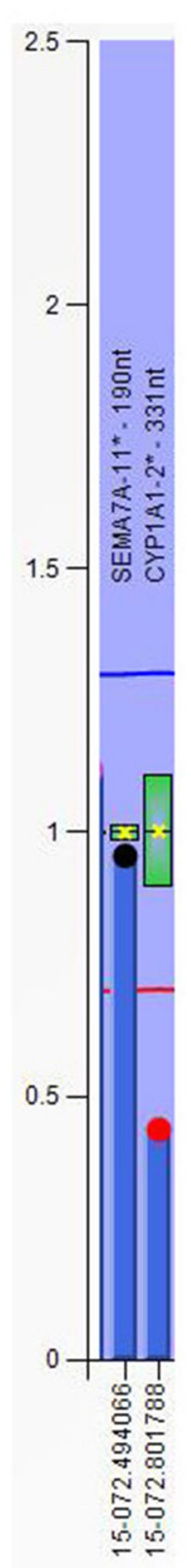

D

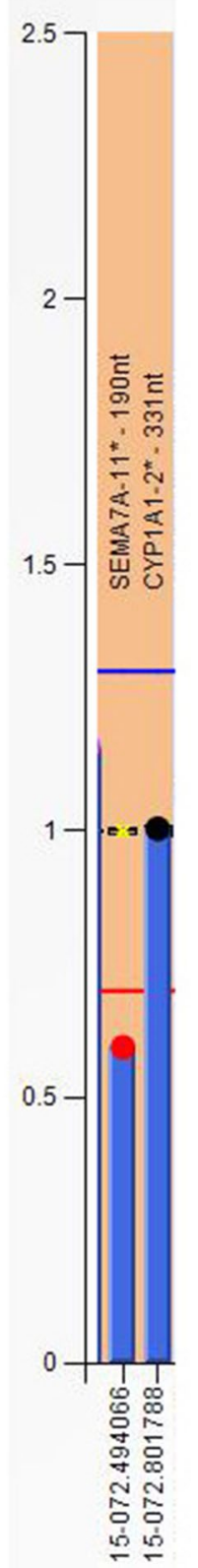

E

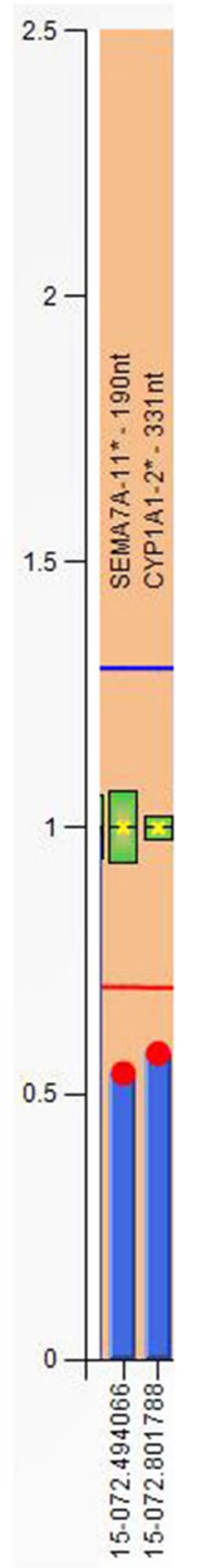

Fig. 2 Columns of MLPA P245 results. X-axis represents MLPA probes. Y-axis represents probe dosage ratio. The blue line indicates probe dosage ratio of 1.35, and ratio above this line represents duplication. The red line indicates probe dosage ratio of 0.65 , and ratio below this line represents deletion. Ratios between 0.85 and 1.15 are considered as normal. A A control with normal copy probes. B Case 1 carries CYP1A1-2 homozygous deletion. C Mother of case 1 carries CYP1A1-2 heterozygous deletion. D Case 3 carries SEMA7A-11 heterozygous deletion. E Case 4 carries CYP1A1-2 and SEMA7A-11 heterozygous deletion. MLPA: Multiplex ligation-dependent probe amplification

SEMA7A-11 probes (Fig. 2). All five cases were further confirmed to have deletions at $15 \mathrm{q} 24$ by MLPA P371 assay, including those with single probe abnormalities by $\mathrm{P} 245$ assay, which ruled out the possibility of probe binding sequence mutation. In detail, cases 4 and 5 showed heterozygous deletion at all nine probes; cases 2 and 3 had heterozygous deletions at two probes of the $S E M A 7 A$ gene; case 1 had homozygous deletions at two probes of the $C Y P 1 A 1$ gene (Fig. 3). Parental analysis revealed that the deletions were de novo in cases 2 , 3,4 , and 5 . The deletion of Case 1 was inherited from 


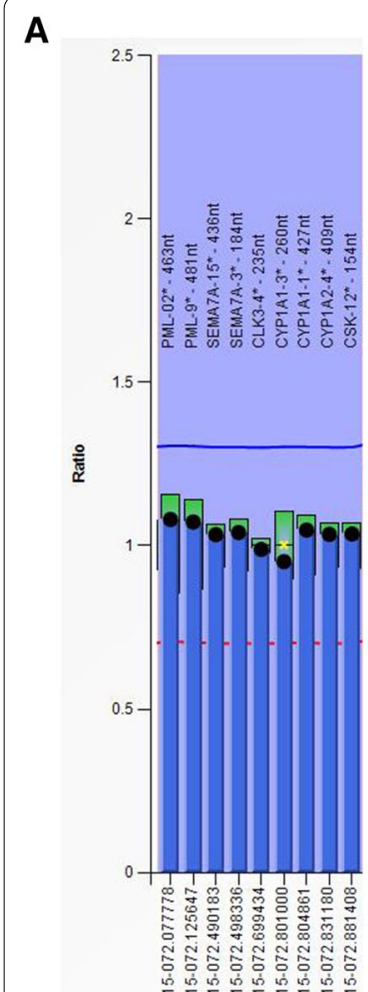

B

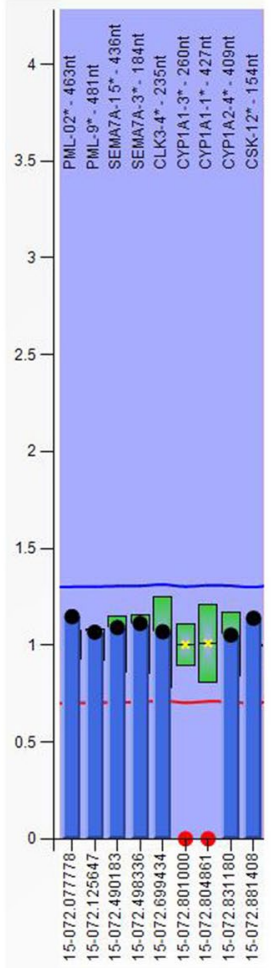

C

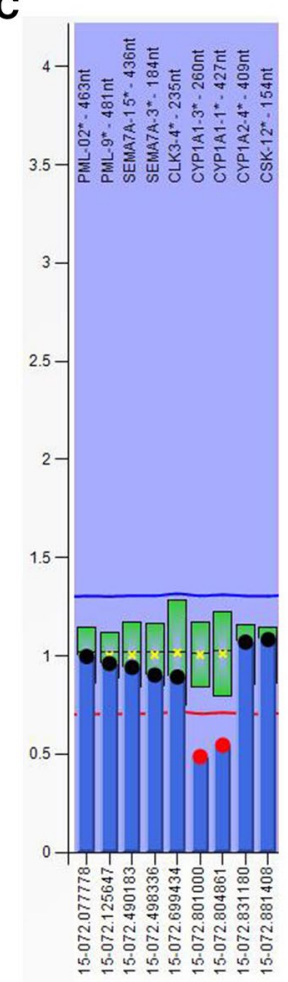

D

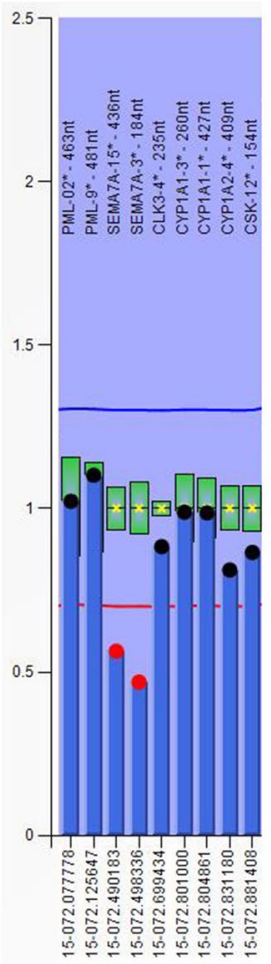

E

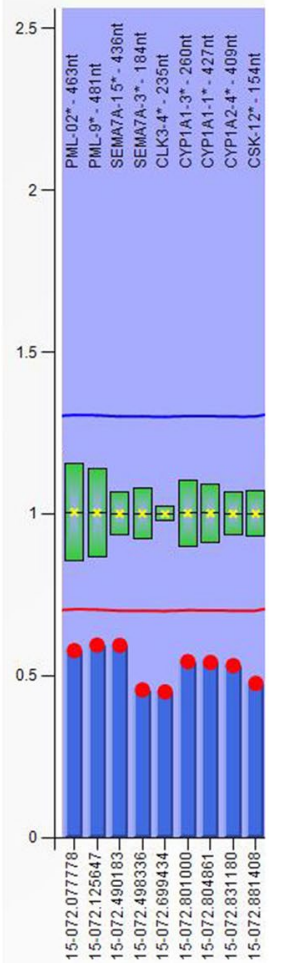

Fig. 3 Columns of MLPA P371 results. X-axis represents MLPA probes. Y-axis represents probe dosage ratio. The blue line indicates probe dosage ratio of 1.35 , and ratio above this line represents duplication. The red line indicates probe dosage ratio of 0.65 , and ratio below this line represents deletion. Ratios between 0.85 and 1.15 are considered as normal. A A control with normal copy probes. B Case 1 carries CYP1A1-1 and CYP1A1-3 homozygous deletion. C Mother of case 1 carries CYP1A1-1 and CYP1A1-3 heterozygous deletion. D Case 3 carries SEMA7A-3 and SEMA7A-15 heterozygous deletion. E Case 4 carries heterozygous deletion from PML to CSK probes. MLPA: Multiplex ligation-dependent probe amplification

her mother, who had heterozygous deletions at the same probes; her father was normal. Detailed results of MLPA tests are shown in Table 1.

\section{Clinical phenotypes of cases with 15 q24 microdeletion}

Cases 2, 3, 4, and 5 had varying degrees of speech or language difficulties from being unable to speak a complete sentence to nonverbal vocabulary. Besides, they manifested motor delay, intellectual disability, and neurobehavioral disorders, including impairment in social interaction, poor response when called, and absence of pointing. Individual children also showed special facial appearance, hyperactivity, and abnormal behaviors. Specifically, case 5 had wide eye distance and strabismus; cases 2 and 3 were hyperactive; case 3 liked to listen to songs repetitively and jumped aimlessly. These children were tested using the childhood autism rating scale (CARS) [6] to assess the existence and severity of autism. Case 3 had a score of 30, meeting the critical value (scores greater than or equal to 30 denote autism, with a score between 30 and 36 considered as mild); cases 2,4 , and 5 had scores of $<30$. Case 1, a baby girl with CYP1A1 probes homozygous deletion, presented with severe laryngeal stridor and lower limb swelling. She had obvious three concave sign, with a respiration rate of 35 times per minute and a heart rate of 130 times per minute. She had suffered from pneumonia and pyemia before. She passed away shortly after being admitted to the pediatric emergency ward. However, her mother, who also carried CYP1A1 probes heterozygous deletion presented as normal. Clinical information and phenotypes are shown in Table 1.

\section{Discussion}

Chromosome 15 band q24 is a complex genomic region with five LCRs, referred to as A, B, C, D, and E. These LCRs can promote NAHR at meiosis, resulting in deletion of the interval sequence. Most deletions are between 1.7 to $6.1 \mathrm{Mb}$ in size, encompassing a small critical region spanning 1.1 Mb in 15q24.1 LCR B-C [1, 3]. MLPA P245 and P371 probe mixes have 11 probes scattered in this small region. Cases 4 and 5 had heterozygous deletions 
Table 1 Clinical information for the cases with 15q24 deletions

\begin{tabular}{|c|c|c|c|c|c|c|c|}
\hline \multirow[t]{2}{*}{ Case number } & \multirow[t]{2}{*}{ Sex } & \multirow[t]{2}{*}{ Age } & \multirow[t]{2}{*}{ Variation } & \multirow[t]{2}{*}{ Oringin } & \multicolumn{2}{|c|}{ Abnormal probes } & \multirow[t]{2}{*}{ Clinical manifestations } \\
\hline & & & & & P245 & P371 & \\
\hline 1 & Female & 55 days & $\begin{array}{l}15 q 24 \\
\text { homozygous deletion }\end{array}$ & Matermal & CYP1A1-2 & $\begin{array}{l}\text { CYP1A1-1 } \\
\text { CYP1A1-3 }\end{array}$ & $\begin{array}{l}\text { Laryngeal stridor, } \\
\text { Lower limbs swelling }\end{array}$ \\
\hline Mother of case 1 & Female & 32 years & $\begin{array}{l}15 q 24 \\
\text { heterozygous deletion }\end{array}$ & Unknown & CYP1A1-2 & $\begin{array}{l}\text { CYP1A1-1 } \\
\text { CYP1A1-3 }\end{array}$ & Normal \\
\hline 2 & Male & 2 years & $\begin{array}{l}15 q 24 \\
\text { heterozygous deletion }\end{array}$ & De novo & SEMA7A-11 & $\begin{array}{l}\text { SEMA7A-15 } \\
\text { SEMA7A-3 }\end{array}$ & $\begin{array}{l}\text { Speech or language difficulty, little vocabulary } \\
\text { Motor delay, walked at } 18 \text { months } \\
\text { Poor response when called } \\
\text { Absence of pointing } \\
\text { Social interaction impairment } \\
\text { Hyperactivity } \\
\text { DQ: } 72 \\
\text { CARS: } 19\end{array}$ \\
\hline 3 & Female & 3 years & $\begin{array}{l}15 q 24 \\
\text { heterozygous deletion }\end{array}$ & De novo & SEMA7A-11 & $\begin{array}{l}\text { SEMA7A-15 } \\
\text { SEMA7A-3 }\end{array}$ & $\begin{array}{l}\text { Speech or language difficulty, nonverbal } \\
\text { vocabulary } \\
\text { Abnormal behavior, listen to songs repetitively, } \\
\text { jump aimlessly } \\
\text { Poor response when called } \\
\text { Absence of pointing } \\
\text { Social interaction impairment } \\
\text { No eye contact } \\
\text { Unable to follow instruction } \\
\text { Hyperactivity } \\
\text { Timid } \\
\text { DQ: } 53 \\
\text { CARS: } 30\end{array}$ \\
\hline 4 & Female & 3 years & $\begin{array}{l}15 q 24 \\
\text { heterozygous deletion }\end{array}$ & De novo & $\begin{array}{l}\text { CYP1A1-2 } \\
\text { SEMA7A-11 }\end{array}$ & $\begin{array}{l}\text { PML-2 } \\
\text { PML-9 } \\
\text { SEMA7A-15 } \\
\text { SEMA7A-3 } \\
\text { CLK3-4 } \\
\text { CYP1A1-3 } \\
\text { CYP1A1-1 } \\
\text { CYP1A2-4 } \\
\text { CSK-12 }\end{array}$ & $\begin{array}{l}\text { Speech or language difficulty, unable to speak a } \\
\text { complete sentence } \\
\text { Motor delay, walked at } 19 \text { months } \\
\text { Abnormal behavior, } \\
\text { Unable to follow instruction } \\
\text { DQ: } 62 \\
\text { CARS: } 27\end{array}$ \\
\hline 5 & Female & 3 years & $\begin{array}{l}15 q 24 \\
\text { heterozygous deletion }\end{array}$ & De novo & $\begin{array}{l}\text { CYP1A1-2 } \\
\text { SEMA7A-11 }\end{array}$ & $\begin{array}{l}\text { PML-2 } \\
\text { PML-9 } \\
\text { SEMA7A-15 } \\
\text { SEMA7A-3 } \\
\text { CLK3-4 } \\
\text { CYP1A1-3 } \\
\text { CYP1A1-1 } \\
\text { CYP1A2-4 } \\
\text { CSK-12 }\end{array}$ & $\begin{array}{l}\text { Speech or language difficulty, speaking single } \\
\text { word } \\
\text { Motor delay, walked at } 19 \text { months } \\
\text { Poor understanding } \\
\text { Special facial appearance, wide eye distance } \\
\text { DQ: } 81 \\
\text { CARS: } 22\end{array}$ \\
\hline
\end{tabular}

$D Q$ developmental quotient, CARS childhood autism rating scale

at all 11 probes, indicating that the deletions covered this 1.1 Mb interval. Cases 2 and 3 had heterozygous deletion at probes of only the SEMATA gene, suggesting that the fragments involved were between the locations of the PML $(72.11 \mathrm{Mb})$ and $C L K 3(72.68 \mathrm{Mb})$ genes and that the deletion sizes were less than $0.57 \mathrm{Mb}$. Cases 2 and 3 both had obvious developmental delays and neurobehavioral features, illustrating that the haploinsufficiency of this tiny fragment could lead to the main manifestations of $15 \mathrm{q} 24$ deletion syndrome. This interval contains the STRA6 (signaling receptor and transporter of retinol STRA6), CCDC33 (coiled-coil domain containing
33), CYP11A1 (cytochrome P450 family 11 subfamily A member 1), SEMA7A, and UBL7 (ubiquitin-like 7) genes, which may contribute to the corresponding phenotypes of the syndrome. SEMA7A is expressed in neuron. It enhances central and peripheral axon growth, and is required for proper axon tract formation during embryonic development [7]. STRA6 is involved in cellular uptake of vitamin A [8]. Haploinsufficiency of STRA6 may cause a group of congenital malformations, including microphthalmia, cardiovascular malformations, diaphragmatic hernia, and mental retardation [9]. The function of $C C D C 33$ gene is rarely reported. A recent 
study demonstrated CCDC33 may have potential roles in immunity through interacting at a distance with and modulating ISLR2 (immunoglobulin superfamily containing leucine rich repeat 2) gene expression [10]. CYP11A1 encodes a mitochondrial cholesterol side-chain cleavage enzyme that catalyzes side-chain hydroxylation and cleavage of cholesterol to pregnenolone, the precursor of most steroid hormones [11]. The haploinsufficiency of CYP11A1 may contribute to the genital abnormalities in patients with 15q24 deletion syndrome [12]. Little is known about UBL7 (BMSC-UbP), which possesses a ubiquitin-associated domain [13]. It is widely expressed and may play a role by regulating substrate protein expression through ubiquitination modification.

The $15 \mathrm{q} 24$ deletion occurs de novo in most reported cases. To the best of our knowledge, only one study described three patients in the same family [14]. In this study, case 1 and her mother had deletions at the same probes, suggesting that her mother's deletion was delivered to her. However, case 1 had homozygous deletion, whereas her mother had heterozygous deletion. This 55 days old baby manifested severe laryngeal stridor and lower limb swelling. We did not observe any developmental problems because she was too young, but she had suffered from pneumonia and pyemia before, suggesting that her immunity was poor. Unfortunately, she passed away shortly after being admitted to the pediatric emergency ward. However, her mother, who carried heterozygous deletion, was asymptomatic and gave birth to a healthy baby 1 year later, indicating incomplete penetrance of this mutation and that the consequence of homozygous deletion is more serious. Combined with the results of P245 and P371 assays, we concluded that the deletion was small and between the locations of the CLK3 (72.71 Mb) and CYP1A2 (72.82 Mb) genes, with a deletion size $<0.11 \mathrm{Mb}$. Interestingly, we applied next generation sequencing (NGS) based CNV-seq to further determine this tiny deletion-this approach can detect structural abnormalities larger than $100 \mathrm{~kb}$-but did not get a positive result (data not shown). This suggests that the deletion size is actually smaller than $0.1 \mathrm{Mb}$ and exceeds the resolution of CNV-seq. We also tested the sample with the MS-MLPA P028 assay, which was used to analyze $\mathrm{CpG}$ island methylation of the $15 \mathrm{q} 11$ region. The negative result (data not shown) ruled out the possibilities of entire chromosome 15 uniparental disomy (UPD) and Prader-Willi syndrome (deletion or UPD). We speculated that the homozygous deletion might be due to segmental UPD or paternal loss of this tiny fragment. We wanted to use SNP array to confirm it, but no DNA sample left for us to do this. There are two genes in this interval, EDC3 (enhancer of $m R N A$ decapping 3 ) and CYP1A1. EDC3 is associated with mRNA degradation
[15]. Mutations in EDC3 have been identified in autosomal recessive intellectual disability, indicating its crucial role in neurodevelopment [16]. CYP1A1 mediates the metabolism of fatty acids, steroid hormones, vitamins, and drugs. It can metabolize some polycyclic aromatic hydrocarbons (PAHs) to carcinogenic intermediates [17], and is important in defining the efficacy and toxicity/carcinogenicity of drugs and foreign compounds [18].

Genomic CNV is a risk factor for autism spectrum disorder (ASD). Certain CNVs, such as 22q13 deletion, 16p11.2 deletion/duplication, 22q11.2 deletion/duplication, and 15q24 duplication have been found in patients with ASD [19]. ASD was also reported to be an additional phenotype in 15q24 deletion syndrome [20, 21]. Recently, a study observed a critical interval of $0.65 \mathrm{Mb}$ in the 15q24 LCR A-B region, which might contribute to ASD [22]. In our study, case 3 , who had a deletion of $<0.57 \mathrm{Mb}$ in the 15q24.1 LCR B-C region, manifested ASD features, including nonverbal communication, social interaction impairment, restricted and repetitive behaviors, hyperactivity, no eye contact, and poor response when called. According to CARS, she had a score of 30 and was diagnosed with mild ASD. She was referred to pediatric neurology for further evaluation and treatment. The aforementioned SEMA7A gene plays a critical role in neurodevelopment. A recent study identified SEMA7A as a critical cue that restricts serotonergic innervation in the spinal cord [23]. In PTZ-kindled epileptic rats, Sema7A was upregulated in the epileptic brain and played a potential role in the regulation of seizure activity [24]. SEMA5A (semaphorin 5A), another gene of the semaphorin family, was identified to be an ASD-associated gene, and there was evidence of decreased expression of this gene in patients with autism [25, 26]. However, the relationship between SEMA7A and ASD is not clear. Further investigation is required to determine the contribution of SEMA7A to the complex etiology of ASD.

In conclusion, this study revealed the prevalence of chromosome 15q24 microdeletion in Chinese pediatric patients with developmental delay and/or intellectual disability. We present additional evidence of $15 \mathrm{q} 24$ microdeletion syndrome with genetic and clinical findings. We identified two smaller deletions $(<0.57 \mathrm{Mb}$ and $<0.11 \mathrm{Mb}$ ) within the $15 \mathrm{q} 24.1 \mathrm{LCR} \mathrm{B}-\mathrm{C}$ region that have not been reported in previous data, and delineated a critical region for core phenotypes in 15q24 microdeletion syndrome. Our results will increase awareness of these disruptive mutations among pediatricians and provide meaningful information for their daily practice.

\section{Abbreviations}

ACGH: Array comparative genomic hybridization; ASD: Autism spectrum disorder; CARS: Childhood autism rating scale; CCDC33: Coiled-coil domain 
containing 33; CLK3: CDC like kinase 3; CNV: Copy number variation; CSK: C-terminal Src kinase; CYP1A1: Cytochrome P450 family 1 subfamily A member 1; CYP1A2: Cytochrome P450 family 1 subfamily A member 2; CYP11A1: Cytochrome P450 family 11 subfamily A member 1; EDC3: Enhancer of mRNA decapping 3; ISLR2: Immunoglobulin superfamily containing leucine rich repeat 2; LCR: Low copy repeat; LOH: Loss of heterozygosis; MLPA: Multiplex ligation-dependent probe amplification; NAHR: Nonallelic homologous recombination; NGS: Next generation sequencing; PAHs: Polycyclic aromatic hydrocarbons; PML: PML nuclear body scaffold; SEMA5A: Semaphorin 5A; SEMA7A: Semaphorin 7A; STRA6: Signaling receptor and transporter of retinol STRA6; UBL7: Ubiquitin-like 7; UPD: Uniparental disomy.

\section{Supplementary Information}

The online version contains supplementary material available at https://doi. org/10.1186/s13039-021-00574-x.

Additional file 1. MLPA probes for chromosome 15q24.

\section{Acknowledgements}

We thanked all the participants and the families in this study for their cooperation.

\section{Authors' contributions}

YYZ1 analyzed and interpreted the MLPA data and wrote the manuscript. XLL and HMG analyzed and interpreted the clinical data of patients. CWT and ZBJ analyzed and interpreted the karyotyping data. YYZ2 modified the manuscript. We ensure that all authors have read and approved the manuscript.

\section{Funding}

This study was funded by grant from the National Key R\&D Program of China (Grant: 2016YFC1000700 and 2016YFC1000702).

\section{Availability of data and material}

The datasets generated and/or analyzed during the current study are available in the figshare repository (https://figshare.com/articles/figure/Untitled_Item/ 14832789).

\section{Declarations}

\section{Ethics approval and consent to participate}

This study was approved by Ethics Committee of Shengjing Hospital of China Medical University. Written informed consents to participate were obtained from parents or legal guardians of the cases who were under the age of 16 .

\section{Consent for publication}

Written informed consent for publication of identifying images and clinical details were obtained from parents or legal guardians of the cases who were under the age of 16 .

\section{Competing interests}

The authors declared no potential conflict of interest.

Received: 23 August 2021 Accepted: 3 November 2021

Published online: 18 December 2021

\section{References}

1. Magoulas PL, El-Hattab AW. Chromosome 15q24 microdeletion syndrome. Orphanet J Rare Dis. 2012;4(7):2.

2. Cooper GM, Coe BP, Girirajan S, et al. A copy number variation morbidity map of developmental delay. Nat Genet. 2011;43(9):838-46.

3. Mefford H, Shur N, Rosenfeld J (2012) 15q24 Microdeletion Syndromeretired chapter, for historical reference only. In: Adam MP, Ardinger $H H$, Pagon RA, Wallace SE, Bean LJH, Mirzaa G, Amemiya A, editors. GeneReviews ${ }^{\circledR}$ [Internet]. Seattle (WA): University of Washington, Seattle; 1993-2021.
4. Andrieux J, Dubourg C, Rio M, et al. Genotype-phenotype correlation in four $15 q 24$ deleted patients identified by array-CGH. Am J Med Genet A. 2009:149A(12):2813-9.

5. Zhang Y, Liu X, Gao H, et al. Identifying of 22q11.2 variations in Chinese patients with development delay. BMC Med Genom. 2021;14(1):26.

6. Kaat A, Lecavalier L. Childhood Autism Rating Scale. In: Volkmar F.R. (eds) Encyclopedia of autism spectrum disorders. Springer, New York.

7. Pasterkamp RJ, Peschon JJ, Spriggs MK, et al. Semaphorin 7A promotes axon outgrowth through integrins and MAPKs. Nature. 2003;424(6947):398-405.

8. Kawaguchi R, Yu J, Honda J, et al. A membrane receptor for retinol binding protein mediates cellular uptake of vitamin A. Science. 2007:315(5813):820-5.

9. Pasutto F, Sticht H, Hammersen G, et al. Mutations in STRA6 cause a broad spectrum of malformations including anophthalmia, congenital heart defects, diaphragmatic hernia, alveolar capillary dysplasia, lung hypoplasia, and mental retardation. Am J Hum Genet. 2007;80(3):550-60.

10. Lees JA, Ferwerda B, Kremer PHC, et al. Joint sequencing of human and pathogen genomes reveals the genetics of pneumococcal meningitis. Nat Commun. 2019;10(1):2176.

11. Slominski AT, Li W, Kim TK, et al. Novel activities of CYP11A1 and their potential physiological significance. J Steroid Biochem Mol Biol. 2015;151:25-37.

12. Klopocki E, Graul-Neumann LM, Grieben U, et al. A further case of the recurrent $15 q 24$ microdeletion syndrome, detected by array CGH. Eur J Pediatr. 2008;167(8):903-8.

13. Liu S, Yu Y, An H, et al. Cloning and identification of a novel ubiquitin-like protein, BMSC-UbP, from human bone marrow stromal cells. Immunol Lett. 2003;86(2):169-75.

14. Samuelsson L, Zagoras T, Hafström M. Inherited $15 q 24$ microdeletion syndrome in twins and their father with phenotypic variability. Eur J Med Genet. 2015;58(2):111-5.

15. Scheller $U$, Pfisterer $K$, Uebe $S$, et al. Integrative bioinformatics analysis characterizing the role of EDC3 in mRNA decay and its association to intellectual disability. BMC Med Genom. 2018;11(1):41.

16. Ahmed I, Buchert R, Zhou M, et al. Mutations in DCPS and EDC3 in autosomal recessive intellectual disability indicate a crucial role for mRNA decapping in neurodevelopment. Hum Mol Genet. 2015;24(11):3172-80.

17. Nebert DW, Dalton TP. The role of cytochrome P450 enzymes in endogenous signalling pathways and environmental carcinogenesis. Nat Rev Cancer. 2006;6(12):947-60.

18. Kapelyukh Y, Henderson CJ, Scheer N, et al. Defining the Contribution of CYP1A1 and CYP1A2 to Drug Metabolism Using Humanized CYP1A1/1A2 and Cyp1a1/Cyp1a2 Knockout Mice. Drug Metab Dispos. 2019;47(8):907-18.

19. Marshall CR, Noor A, Vincent JB, et al. Structural variation of chromosomes in autism spectrum disorder. Am J Hum Genet. 2008:82(2):477-88.

20. Autism Genome Project Consortium, Szatmari P, Paterson AD, et al. (2007) Mapping autism risk loci using genetic linkage and chromosomal rearrangements. Nat Genet. 39(3):319-328.

21. McInnes LA, Nakamine A, Pilorge M, et al. A large-scale survey of the novel 15q24 microdeletion syndrome in autism spectrum disorders identifies an atypical deletion that narrows the critical region. Mol Autism. 2010;1(1):5.

22. Liu $Y$, Zhang $Y$, Zarrei $M$, et al. Refining critical regions in $15 q 24$ microdeletion syndrome pertaining to autism. Am J Med Genet B Neuropsychiatr Genet. 2020;183(4):217-26.

23. Loy K, Fourneau J, Meng N, et al. Semaphorin 7 A restricts serotonergic innervation and ensures recovery after spinal cord injury. Cell Mol Life Sci. 2021;78(6):2911-27

24. Deng J, Xu T, Yang J, et al. Sema7A, a brain immune regulator, regulates seizure activity in PTZ-kindled epileptic rats. CNS Neurosci Ther. 2020;26(1):101-16.

25. Melin M, Carlsson B, Anckarsater $\mathrm{H}$, et al. Constitutional downregulation of SEMA5A expression in autism. Neuropsychobiology. 2006;54(1):64-9.

26. Cheng Y, Quinn JF, Weiss LA. An eQTL mapping approach reveals that rare variants in the SEMA5A regulatory network impact autism risk. Hum Mol Genet. 2013;22(14):2960-72. 


\section{Publisher's Note}

Springer Nature remains neutral with regard to jurisdictional claims in published maps and institutional affiliations.

- fast, convenient online submission

- thorough peer review by experienced researchers in your field

- rapid publication on acceptance

- support for research data, including large and complex data types

- gold Open Access which fosters wider collaboration and increased citations

- maximum visibility for your research: over $100 \mathrm{M}$ website views per year

At BMC, research is always in progress.

Learn more biomedcentral.com/submissions 